LBNL-47888

\title{
DESIGN OPTIONS FOR CLOTHES WASHERS
}

October 1996

\author{
Peter J. Biermayer \\ LAWRENCE BERKELEY NATIONAL LABORATORY \\ Energy \& Environment Division \\ Berkeley, CA 94720
}

\author{
Prepared for \\ U.S. DEPARTMENT OF ENERGY \\ Office of Codes and Standards
}

This work was supported by the Assistant Secretary for Energy Efficiency and Renewable Energy, Office of Building Technology, State and Community Programs, Office of Codes and Standards, of the U.S. Department of Energy under Contract No. DE-AC03-76SF00098. 


\section{TABLE OF CONTENTS}

\section{DESIGN OPTIONS FOR CLOTHES WASHERS}

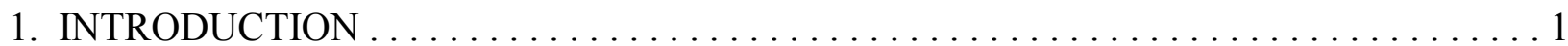

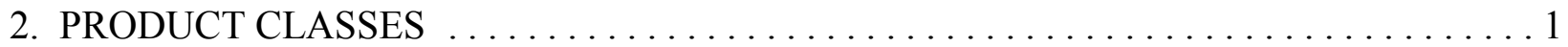

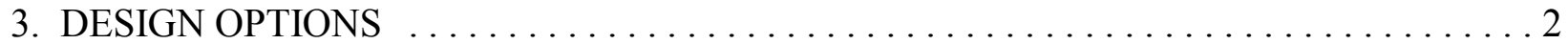

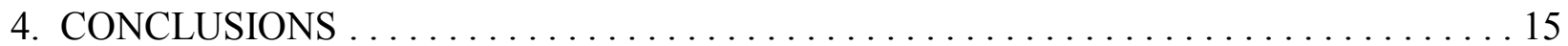

\section{LIST OF TABLES}

Table 1 Current Product Classes \& Efficiency Standards $\ldots \ldots \ldots \ldots \ldots \ldots \ldots \ldots \ldots \ldots \ldots \ldots$

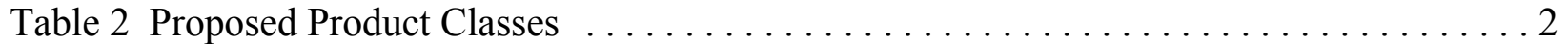

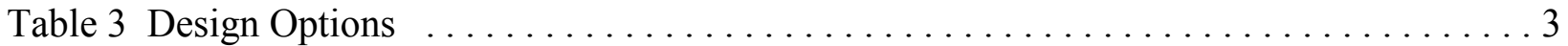

Table 4 Design Options Eliminated from Further Analysis $\ldots \ldots \ldots \ldots \ldots \ldots \ldots \ldots \ldots \ldots$

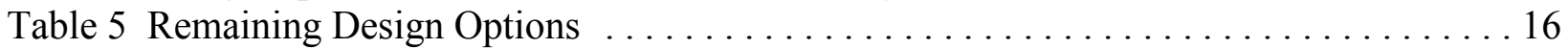




\section{Design Options for Clothes Washers}

\section{INTRODUCTION}

This report discusses possible design options for improving the energy efficiency of standard capacity, residential clothes washers.

The procedure used in this design option analysis is based on a Department of Energy (DOE) interpretive ruling outlining process improvement measures [1]. After the different appliances subject to possible regulation are ranked, potential design options are identified as the next step in the process of promulgating appliance efficiency standards. Screening factors are then used to determine if any design options should be eliminated from further consideration. Much of the input used for screening design options was provided by clothes washer manufacturers. Other sources include trade publications and the Association of Home Appliance Manufacturers (AHAM).

Although (under the new process) the design option stage of the analysis now precedes an Advance Notice of Proposed Rulemaking (ANOPR), responses to the original ANOPR [2], data previously collected from manufacturers, and existing input from AHAM and other stakeholders will still be considered in this report. The DOE intends to issue a Supplemental Advance Notice of Proposed Rulemaking in the future.

\section{PRODUCT CLASSES}

Appliance features that provide utility to the consumer are incorporated into the analysis through the creation of product classes. Classes are a subset of appliance types. For example, clothes washers are an appliance type, but a compact clothes washer is a product class. Appliance types are segregated into separate classes to which different energy-efficiency standards apply. DOE differentiates classes by capacity or other performance-related features that provide utility to the consumer and affect efficiency. In general, classes are defined using data collected in discussions with appliance manufacturers, trade associations, and other interested parties. Those classes for which no DOE test procedure has been specified are omitted from further analysis.

Currently, clothes washers are separated into the product classes shown in Table 1. The corresponding minimum efficiency requirements which became effective May 14, 1994 are also provided [3]. 
Table 1. Current Product Classes \& Efficiency Standards

\begin{tabular}{ll}
\hline Product Class & Efficiency Standard \\
\hline Compact top loading & $\mathrm{EF} \geq 0.90 \mathrm{ft}^{3} /(\mathrm{kWh} / \mathrm{cycle})$ \\
Standard top loading & $\mathrm{EF} \geq 1.18 \mathrm{ft}^{3} /(\mathrm{kWh} / \mathrm{cycle})$ \\
Semi-automatic top loading & Must have unheated rinse option \\
Front loading & Must have unheated rinse option \\
Suds saving & Must have unheated rinse option \\
\hline
\end{tabular}

In a previous rulemaking [4], the terms top loading and front loading were used to refer to vertical and horizontal axis clothes washers, respectively. Since horizontal axis machines can be manufactured in a top loading configuration, product class distinction - based on how clothes are loaded - is no longer made. Instead, vertical and horizontal axis washers are considered as design strategies that manufacturers can use to achieve different efficiency levels. For the present analysis, the product classes in Table 2 were considered.

Table 2. Proposed Product Classes

\begin{tabular}{cc}
\hline Product Class & Definition \\
\hline Compact & less than $1.6 \mathrm{ft}^{3}$ capacity \\
Standard & $1.6 \mathrm{ft}^{3}$ or greater capacity \\
\hline
\end{tabular}

In this report, since data were not available for the compact class, only standard capacity clothes washers will be discussed.

\section{DESIGN OPTIONS} energy.

Design options are changes in clothes washer design that may have the potential to save

The DOE issued an ANOPR on November 14, 1994, that proposed design options for increasing clothes washer efficiency [5]. A questionnaire based on these design options was sent to AHAM for distribution to its clothes washer manufacturer members. The questionnaire requested data on the energy use and cost of design options. After the initial questionnaire was distributed, workshops were held between stakeholders including AHAM, manufacturers, and DOE. These interactions resulted in modifications and additions to the initial design option list.

Several of the original ANOPR design options were renamed to better define their technology. Microprocessor controls \& fuzzy logic was renamed advanced controls/sensor. Configuration/tolerance of inner and outer tubs was changed to tighter tub tolerance. Higher spin speed was redefined as improved water extraction and was separated into four different values 
for remaining moisture content (RMC); $50 \%, 40 \%, 35 \%$, and $30 \%$. The RMC design option is the same in all four cases but it varies in the amount of final moisture content of the cloth. Different costs and energy usages are required to achieve the different levels of RMC.

Several design options were split into two or more options. Improved fill control was originally interpreted differently by individual manufacturers (with large differences in cost and energy savings) and was therefore split into two options: improved fill control and automatic fill control. The horizontal axis design option was separated into two design options: horizontal axis and horizontal axis with recirculation.

Table 3 shows the final design options considered in this analysis.

Table 3. Design Options

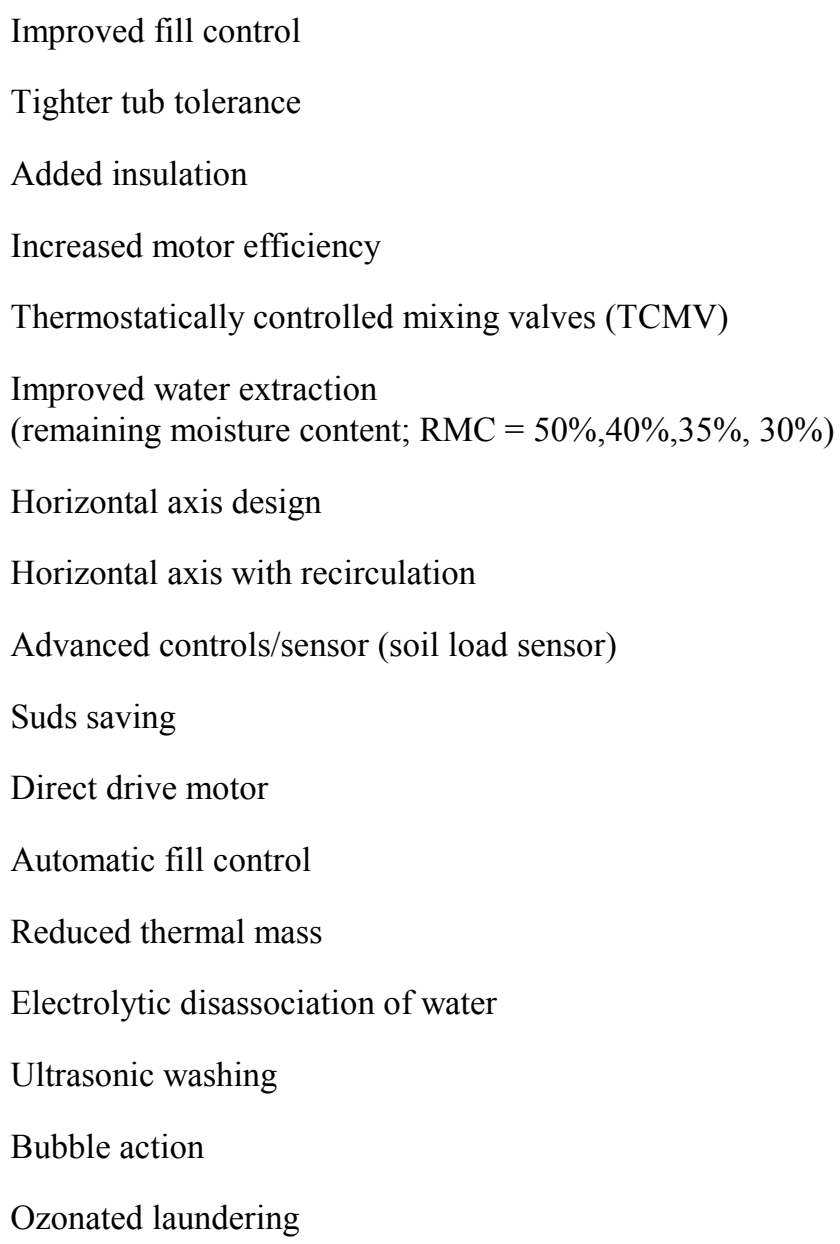

Some of the design options in Table 3 are eliminated from further consideration (later in this report) if one of the following criteria are not met [6]: 
1) Technological Feasibility. Technologies incorporated in commercial products or in working prototypes will be considered technologically feasible.

2) Practicability to Manufacture, Install and Service. If mass production of a technology

in commercial products and reliable installation and servicing of technology could be achieved on the scale necessary to serve the relevant market at the time of the effective date of the standard, then that technology will be considered practicable to manufacture, install and service.

3) No adverse Impacts on Product Utility or Product Availability.

4) No adverse Impacts on Health or Safety.

The reasons for eliminating a design option shown in Table 3 (or keeping for further consideration) are discussed in the individual descriptions of the design options outlined below. The design options that are not recommended for elimination in this report will be analyzed further in a later report. In this later report, the efficiency and cost of design options and combinations of design options will be analyzed.

Included in the discussion of design options are limiting performance factors (if the same factor was submitted by two or more manufacturers). These limiting performance factors describe parameters affected by a design option. Typically, these factors affect the utility of the clothes washer. A limiting performance factor does not necessarily exclude a design option from further analysis but describes performance factors that are affected by a design option and should be taken into consideration.

\section{Baseline Model}

A clothes washer baseline model is used as a reference for evaluating the energy saving potential and increased manufacturing costs of various design options. The potential for energy savings is based on a proposed future DOE test procedure (Appendix J1) [7]. This test procedure will take effect only when a new clothes washer standard is enacted.

The baseline represents the typical vertical axis washer with an energy efficiency just above the minimum allowable, as specified by updates to the National Appliance Energy Conservation Act (NAECA). Currently, all standard size washers must achieve the minimum allowed energy factor of $1.18 \mathrm{ft}^{3} / \mathrm{kWh}$, as rated according to the existing DOE test procedure. The baseline model will be assumed to have a plastic tub, non-thermally controlled mixing valves, an unheated rinse and the capability to achieve a $62 \%$ remaining moisture content on the normal spin cycle. 


\section{Improved fill control}

This design option is defined as improving the tolerance on existing wash water fill sensing. This can be accomplished by reducing tolerances of presently used pressure sensors or improving switch design. This design option relates primarily to vertical axis design washers, although it is sometimes applicable to horizontal axis washers depending on the specific fill control design. In a typical vertical axis washer, one end of an air hose is connected near the bottom of the washer tub and the other end is connected to a pressure switch. As water fills the tub, air in the hose is forced into a smaller volume, thereby increasing the air pressure. The air pressure increases until it activates a pressure switch, which in turn shuts off the water inlet valve. A more accurate water level setting system would avoid overfilling the wash tub, thereby reducing the amount of water and energy used. Limiting performance factors mentioned by manufacturers include: 1) soil removal, 2) gentleness of action, and 3) wear.

One manufacturer said it was not aware of any opportunity to reduce tolerances of presently used pressure sensors. But because several manufacturers provided cost and efficiency data for improving the fill control, it was analyzed as a method to improve clothes washer efficiency.

\section{Tighter tub tolerance}

This design option reduces the space (the annulus) between the inner wash basket and the outer tub. This annulus fills with water, but does not add to the clothes washer capacity. Having less space between the inner wash basket and the outer tub reduces the amount of water required for a fill, thereby saving the energy required to heat it. This option applies primarily to vertical axis washers. In a horizontal axis washer, water only occupies the lower portion of the annulus. Since most of the annulus in a horizontal axis washer is filled with air, a smaller annulus does not yield significant energy savings.

Other considerations are also important in determining an appropriate clearance between basket and tub. Manufacturers state that if the annulus is too small there may be problems with "suds lock", where suds from the wash water remain between the inner wash basket and outer tub. Clearance is also needed to drain water during the spin dry cycle. Also, enough space must be retained to allow for deflection of baskets with out-of-balance loads. Increasing the spin speed of the washer basket during the spin dry cycle may also require a larger space between tub and basket to allow for greater deflection at higher spin speeds. For this reason, tighter tub tolerance was not combined with the improved water extraction design options. Other limiting performance factors mentioned by manufacturers include: 1) noise, 2) vibration, and 3) sand removal. 
One manufacturer stated that the space between inner and outer tubs is already at the minimum. However, tub tolerances vary among manufacturers. Therefore, manufacturer supplied cost and efficiency data were used to estimate the benefit of tightening the tub tolerance.

\section{Added insulation}

This design option adds insulation around the outer wash tub. Because some heat energy is lost through the shell of the clothes washer, adding insulation around the outer tub slightly reduces the water temperature needed for a hot wash. However, since the wash cycle is short, the thermal mass of the water is very high, and the temperature of the tub is relatively low there is very little change in water temperature from adding insulation. Computer simulations performed for a 20 -minute wash cycle at $140^{\circ} \mathrm{F}$ showed that adding one inch of fiberglass insulation relative to no insulation resulted in only a $1-2^{\circ} \mathrm{F}$ increase in water temperature during parts of the wash [8].

Some manufacturers stated that this design option would produce little savings and should be eliminated. Since several manufacturers supplied cost and efficiency data for this design option, it was analyzed as a method to improve clothes washer efficiency.

\section{Increased motor efficiency}

About $10 \%$ of the total electrical energy consumed by a typical clothes washer is used by the electric motor. The typical washing machine has a $1 / 2-2 / 3$ horsepower motor. One manufacturer states that replacing a split-phase motor with a capacitor start motor may increase the efficiency of the motor by $10 \%$ [9]. Limiting performance factors mentioned by manufacturers include: 1) physical size and 2) servicing/installation.

Manufacturers supplied data for this option but suggested that since the motor energy is a small part of the total energy, even a $10 \%$ reduction in motor energy would result in only a $1 \%$ reduction in overall energy consumption. Although only small energy savings would be realized by improving the motor efficiency, it was still considered as a method to improve clothes washer efficiency.

\section{Thermostatically controlled mixing valves $(T C M V S)^{1}$}

This design option achieves energy savings by more accurately controlling inlet water temperature for hot or warm fills. In a typical non-thermostatically controlled water inlet system, two solenoid valves are used; one valve controls hot water fills while the other controls cold water fills. Both solenoid valves are opened if a warm water setting is selected. In the warm wash mode, a fixed fraction of hot and cold water are controlled by flow control devices. For

\footnotetext{
${ }^{1}$ Also referred to as "Thermostatically Controlled Water Valves".
} 
example, a manufacturer may decide to let warm water be $50 \%$ hot and $50 \%$ cold. To reduce hot water energy use, some manufacturers have reduced the warm water temperature by using other ratios such as $40 \%$ hot and $60 \%$ cold.

A thermostatically controlled mixing valve (TCMV) refers to a set of clothes washer valves which sense water temperature and adjust the supply of hot and cold water to maintain a desired warm water temperature [10]. In the June 1996 comments to the DOE test procedure, AHAM commented that it is not necessary to define thermostatically controlled water valves but to define clothes washers with thermostatically controlled water valves. It is likely that DOE will revise the aforementioned definition to that recommended by AHAM: "Clothes washers with thermostatically controlled water valves refer to clothes washers which sense water temperature and adjust the hot water and cold water supplies appropriately to maintain a mixed water temperature" [11].

Energy can be saved with a TCMV by either reducing the hot water temperature or reducing the warm water temperature. For example, the TCMV could be used to lower the hot wash temperature from $135^{\circ} \mathrm{F}$ to $130^{\circ} \mathrm{F}$ by mixing hot water (at $135^{\circ} \mathrm{F}$ test inlet conditions) with cold water. Warm water temperature could be similarly reduced. The energy savings can vary widely depending on the test standard's specified inlet hot water temperature and the selected temperature of the tempered water.

A TCMV design option has the potential to overstate the actual in-home energy savings when tested under laboratory conditions. The magnitude of the discrepancy depends on the proximity of the water heater to the clothes washer. When tested under laboratory conditions, the clothes washer is next to the hot water source, whereas this is generally not the case in the home. As a result of the distance between the hot water source and the clothes washer, there is a temperature drop due to line losses. As a result of the line losses, a clothes washer with a TCMV may use more hot water than predicted under the laboratory testing. Similarly, in a real world application savings will also vary with the temperature of incoming cold water (i.e. ground water). The unheated water temperature will vary with both geographic location and time of year. More energy would likely be saved in cases of warmer inlet water as a TCMV would then reduce the amount of time a hot water valve is open. The amount of savings is also dependent on the set point of the TCMV, the water heater set point, the temperature selection of the wash (hot or warm cycle), and the location of the sensing thermostat controlling the inlet water valves. A limiting performance factor mentioned by more than one manufacturer was soil removal.

Because TCMV's are commercially available on high end machines they were considered as a way to increase clothes washer efficiency. Manufacturers supplied cost and efficiency data for this design option. 


\section{Improved water extraction}

There are several ways to reduce the remaining moisture content (RMC) in the laundry load after the final spin cycle. One method is to increase the spin speed of the wash basket for the final spin cycle. Other ways include: 1) changing the direction of rotation to more evenly distribute clothes, 2) having a longer spin cycle, and 3) increasing the size or number of drainage holes in the washer drum. Since mechanical drying is more efficient than using heat to dry, energy consumption for the combined wash and dry process is reduced.

Limiting performance factors mentioned by manufacturers include: 1) greater wrinkling of clothes, 2) noise and, 3) vibration. Manufacturers state that the washing machine structure would have to be redesigned to handle greater dynamic loads, stresses, deflections, and increased braking. In addition, different spin cycle options would have to be available on a washer to account for the load type. Different fabrics require different maximum spin speeds to avoid clothes damage. The probable, future test procedure (Appendix J1) will most likely assume that the improved water extraction feature will not be used for $25 \%$ of the time that the clothes washer is in use (based on AHAM response to the test procedure Supplemental ANOPR) [12]. Since this feature can be consumer selectable, clothes subject to wrinkling can be washed with a conventional spin cycle option to avoid a wrinkling problem. Some manufacturers were doubtful that RMCs of $35 \%$ and $30 \%$ could be practically obtained.

In laboratory testing, RMCs on commercially available horizontal axis washers ranged from $49 \%$ to $36 \%$ with a $50 / 50$ cotton/polyester cloth load. For the same test load, a vertical axis machine had a 52\% RMC. The washers for the above testing were loaded at 3 pounds per cubic foot of basket capacity [13]. The future DOE test procedure (Appendix J1), generally based on AHAM recommendations, specifies the test load as being closer to 4 pounds per cubic foot of basket capacity [14]. Since the amount of cloth test load has an effect on the RMC achieved, it is unknown whether the above laboratory tested machines can achieve their stated RMC values under future DOE test conditions.

Some manufacturers already have models which can achieve 40\% RMC levels. For example, General Electric applied for a test procedure waiver for a vertical axis washing machine that can achieve RMC levels of less than 40\% [15]. Several European horizontal axis models are able to achieve 40\% RMC including: Asko model 20005; Creda model CWA242; and Miele models W1903, W1918, and W1930 [16].

There do not appear to be any commercially available or known prototype clothes washer that achieves RMCs of $35 \%$ or $30 \%$ and, therefore, these two RMC levels will be eliminated from any further analysis. RMC levels of $50 \%$ and $40 \%$ are analyzed with manufacturer supplied cost and efficiency data. 


\section{Horizontal axis design}

Horizontal axis machines rotate the drum (wash basket) and clothes about a horizontal axis. With this design, the drum does not have to be filled with water to cover the top of the clothes. Therefore, horizontal axis machines use much less water than conventional vertical axis machines. In some designs the washer is first filled to a specified level. As clothes absorb the water, a water level sensor allows more water to enter to maintain the specified level. In this way the water level is matched to the laundry load. Washing performance appears to be equal to that of vertical axis machines. In laboratory testing, horizontal axis machines used on average $40 \%$ less energy and $25 \%$ less water when normalized to clothes container volume. The horizontal axis machines also had a greater soil removal effectiveness [17].

In a previous analysis, it was estimated that less detergent would be needed based on some detergent manufacturers' recommendations [18]. New information now suggests that if a low sudsing detergent is sold in the U.S., detergent use would remain unchanged [19][20].

In the May 8, 1995 data submittal by AHAM [21], one manufacturer commented that there will be many consumer utility issues impacted by the use of a horizontal axis design including:

- $\quad$ Clothes washer water bath will still not be at household water heater settings: A greater portion of the fill water will be affected by thermal losses (since less hot water is used) due to 1) household supply piping, 2) washing machine structure, and 3) clothes load.

- There will be an increased cycle time to complete the washing process: This manufacturer states that there is the need to tumble clothes longer as there is less mechanical action in tumbling than agitation. Multiple rinses will be required to remove higher detergent concentration versus rinses in horizontal axis washers. More time is required to heat water if an internal heater is utilized.

- $\quad$ Loading/unloading accessibility is impaired:

There is a need to stoop to load front loader style horizontal axis washers. A small opening (to load clothes) is required to avoid water leaks. The door is locked to avoid water spillage and therefore garments cannot be added after the cycle has been initiated without draining water. Top-loading horizontal style horizontal axis washers have an "unfriendly" spring-loaded trap door. In addition, excessive reach is required to retrieve garments at bottom of cylinder on top loading style horizontal axis machine.

- $\quad$ Rewiring of electrical system may be required:

A financial impact to consumers may result from having to rewire the electrical system of the home to $240 \mathrm{~V}$ in the washer area if an internal heater is utilized. 
- A new low-sudsing formulated detergent would be required:

Leading detergent manufacturers are still developing detergents for horizontal axis machines. As compared to horizontal axis designs, the detergent cost per load will increase. The dosage is the same or slightly less than horizontal axis designs, not one third of vertical axis designs as claimed by advocates of horizontal axis designs.

Limiting performance factors mentioned by more than one manufacturer include: 1) soil removal, 2) consumer interface (ergonomics), 3) tangling, 4) cycle time, 5) rinsing and 6) suds sensitivity.

Horizontal axis machines are currently commercially available in the United States, and although manufacturers have several concerns over this design, it is analyzed as a method to improve clothes washer efficiency.

\section{Horizontal axis with recirculation}

This design option is a variation on the horizontal axis design option. It differs in that this design uses a pump to circulate water from a sump underneath the rotating drum through a spray nozzle into the interior of the rotating drum. The small amount of water in the bottom of the drum of a standard horizontal axis washer is not required. Less hot water is needed per wash cycle, thereby saving energy.

In the May 8, 1995 data submittal by AHAM, one company commented that they have not been able to verify that a savings exists with recirculation. Limiting factors mentioned by more than one manufacturer include: 1) soil removal, 2) tangling, 3) cycle time, 4) rinsing, and 5) suds sensitivity.

Manufacturers submitted data on cost and energy use for this design option. Electrolux models EW 1550, EW 1450, and EW 1250 use direct spray (eight liters per minute of water/detergent solution is sprayed into the drum by means of a supply valve above the porthole) [22].

\section{Advanced controls/sensor (soil load sensor)}

According to the future DOE test procedure (Appendix J1), "an adaptive control system refers to a clothes washer control system which is capable of automatically adjusting washer operation or washing conditions based on characteristics of the clothes load placed in the clothes container, without allowing or requiring consumer intervention and/or actions." This design option would use sensors to measure the soil load to adjust the wash temperature, agitation and/or tumble cycle time, number of rinse cycles, spin speed, and other parameters. Water and energy use can then be tailored to the load, thereby avoiding washing the clothes more than necessary. The future DOE test procedure (Appendix J1) would account for energy savings due 
to this design option, and in some cases would allow for specific field test procedures to measure energy consumption [23].

The Electrolux Intuition and Zanussi Dialog washing machines use fuzzy logic to weigh laundry loads and regulate the length of the cycle, water level, number of rinses, and drying time [24].AEG unveiled the Öko-Lavamat 6953 in mid-1993. This washing machine incorporates fuzzy logic to optimize the washing process while conserving water usage. The fuzzy logic control determines the absorbency of the items being washed at the earliest stage possible after the start of the washing cycle. The system determines the correct water quantity for clear-water washing and the subsequent rinsing (the phase of washing that uses a majority of the water) [25]. Manufacturers submitted cost and energy data for this design option, therefore, this option will be included in further analysis.

\section{Suds saving}

A suds saving feature allows water from one wash cycle to be reused in the next wash cycle. After agitation, sudsy wash water is pumped into a separate storage tub, remaining there until the next wash cycle. While the water is stored, soil settles to the bottom of the tub. During the next wash cycle, all but an inch of the water is pumped back into the washer tub for use again [26]. Manufacturers have commented that this option saves water but not energy. They also believe that there is low consumer demand for this option and would, therefore, not be used often. In addition, this option cannot be used for all loads or soil conditions. This option is useful only when there is more than one wash cycle per load of laundry, e.g., a pre-wash (which is not typically the case), or if the consumer washed more than one wash load at a time. Subsequent washes could receive diminishing benefits, since the water in the holding tub would cool if left standing too long. A limiting performance factor mentioned by more than one manufacturer for this design option was soil removal.

This design option is currently commercially available. An example is AB Electrolux's Recycle 40. It uses water from the final rinse of one load to use again as the prewash of the next cycle [27]. Maytag features this option as a water saving option on one of its washers.

The future (Appendix J1) DOE test procedure will no longer provide an energy saving benefit for this design option. The two interested parties that commented on this provision during the comment period for the test procedures, were not in favor of retaining credit for this design option [28][29]. In addition, because this option requires an external wash tub, consumer utility is affected. This option is eliminated from further consideration for the above stated reasons.

\section{Direct drive motor}

This design option is primarily intended for use in vertical axis machines. A conventional vertical axis clothes washer uses an induction motor, a mechanical transmission, 
and sometimes a pulley belt. A direct drive motor can replace a conventional motor/transmission system. Rather than using a belt and/or transmission, a motor could be directly connected to the agitator, thereby avoiding transmission (gearbox) losses. Eaton, a motor manufacturer, claims that this will result in less mechanical energy required, i.e., less energy needed to run the agitator motor. This is accomplished by using a Brushless DC (BLDC) motor with electronic controls. Cleanability was not measured by Eaton. In addition, other parameters such as cycle time or spin speed were not kept constant in a comparison test with a conventional washer. For the machines tested, Eaton found savings of about $140 \mathrm{~W}$-hr per cycle or $64 \%$ of motor energy use. When adjusted for the direct drive standby power, this difference drops to about $35 \mathrm{~W}$-hr per cycle or $16 \%$. The direct drive standby power is the energy consumption when the machine is "off". In the "off" mode, the direct drive motor system has a power drain of 4.78 watts. The current DOE test procedure does not account for standby power use. Energy savings could be improved if the standby power loss was decreased [30].

One company submitted a comment that energy losses in the drive system are a very small percent of total energy use. Therefore, savings from a direct drive motor would be minimal. A limiting performance factor mentioned by more than one manufacturer for this design option was physical size.

In Japan, Australia, and Asia, vertical axis direct drive washers are currently available. Some horizontal axis machines also use a direct drive motor. Thus, using manufacturer supplied cost and efficiency data, this design option is analyzed as a method to improve the clothes washer efficiency.

\section{Automatic fill control ${ }^{2}$}

This design option incorporates advanced control technologies to sense the clothes load and adjust the water level accordingly. For a vertical axis machine, this may mean setting the water level to just submerge the clothes load. This design option would overcome the tendency of consumers to manually select a water level greater than required.

Energy is saved in either the vertical or horizontal axis designs by reducing the amount of hot water used in the wash cycle. The future (Appendix J1) DOE test procedure (unlike the existing DOE test procedure) uses an actual clothes load and, therefore, possible savings due to this design option can be measured. Limiting performance factors mentioned by more than one manufacturer for this design option were: 1) gentleness of action and 2) wear.

Washing machines with automatic fill control are available. Test procedure waivers for this design option have been applied for, and in some cases a decision or order has been issued by the DOE. Using manufacturer supplied cost and efficiency data, this design option is analyzed as a method to improve clothes washer efficiency.

\footnotetext{
${ }^{2}$ In the test procedure the terminology used is "adaptive water fill control".
} 


\section{Reduced thermal mass}

This design option uses a plastic tub to reduce the thermal mass that would be heated by the water. Tests by manufacturers indicate that very little energy can be saved this way because the bulk of the thermal mass is contained in the hot water. One manufacturer compared the impact of both porcelain enameled steel and polypropylene outer tubs on water temperature. Both machines were filled with 16 gallons of $140^{\circ} \mathrm{F}$ water and agitated for ten minutes. After ten minutes, there was no significant difference in water temperature between the two machines. Calculations show that if there were no heat losses through the outer tub, the equilibrium temperature for the tested steel tub described above would be $138.9^{\circ} \mathrm{F}$. Therefore, there is little to be gained by decreasing the thermal mass of the outer tub [31].

Plastic outer tubs are commonly used by manufacturers and can be considered as part of the baseline model. There is no practicable way to manufacture washing machines with a lower thermal mass beyond the current practice. Therefore, this design option is eliminated from further analysis.

\section{Electrolytic disassociation of water}

The goal of electrolytic dissociation of water is to reduce hot water usage by substituting the electrolytic production of bleaching agents for the water heating process. A prototype clothes washer with electrolytic dissociation of water has been successfully tested [32]. Although commercial detergents perform better at high temperatures, the same hypochlorite concentration obtained by adding bleaching agents to water can be achieved at low temperatures, if the agents are produced by electrolytic disassociation within the machine. The bleaching action is due to the chemical reaction of the oxygen (derived from the chemical decomposition of the hypochlorite) with the insoluble organic compounds that constitute the soil in the clothes. Together they make soluble compounds that are dissolved in the water.

Electrolytic dissociation was tested in a laboratory electrochemical cell. Medium soiled clothes and white materials were used in the test. The washing cycle test was conducted in two steps. The first was with electrolytic action, which was performed by adding $4 \mathrm{gm} /$ liter of salt to the room temperature water. The second stage was with a commercial detergent at a temperature of $95^{\circ} \mathrm{F}$ to $113^{\circ} \mathrm{F}$. The usual rinses, spinning, and drainage followed. Initial tests showed that energy use dropped from about $2.65 \mathrm{kWh} /$ cycle for a typical washing machine to $1.35 \mathrm{kWh} /$ cycle for the new electrochemical method. The costs of such a system are not available.

Manufacturers do not feel that electrolytic dissociation is a workable approach. Primary concerns are negative effects on garments resulting from the bleaching process and poor consumer acceptance due to their inability to control the chemistry and temperature in the wash 
part of the cycle [33]. Since there are no commercially available or working prototypes for residential use, this design option is eliminated from further consideration.

\section{Ultrasonic washing}

The addition of mechanical energy can reduce the need for hot water (or chemical energy) in the cleaning action of clothes washers. One potential method of delivering the mechanical energy is through ultrasonic vibrations that loosen and remove some of the dirt on the soiled clothes. Such washing machines have been produced by a Japanese firm and were to be marketed in the U.S. One U.S. manufacturer of clothes washers investigated the Japanese product and found that it did not successfully clean clothes. The U.S. firm stated that the Japanese company is an excellent manufacturer of ultrasonic transducers, but does not have experience with clothes washing.

One of the problems with ultrasonic vibration is that clothes are not uniformly exposed to the vibrations generated by the transducers, which means that some areas remain soiled. Additionally, the wash solution and the submerged clothes appear to dissipate much of the energy without being cleaned. Although ultrasonic vibration may be technically feasible, a design producing adequate cleaning action does not appear to have been developed [34].

Since there does not appear to be a commercially available product or a working prototype (that successfully cleans clothes), this design option is eliminated from further analysis.

\section{Bubble action}

Daewoo Electronics, Ltd. has developed an air bubble washing machine. This machine uses a low-profile bottom-hugging impeller typical in Asian-style vertical axis washers and combines it with a six-winged, rotating pulsator shaped to direct water in four directions. This pulsator also distributes air bubbles in different directions. The bubbles are generated by a vibrating bellows which is driven by an electromagnet. Bubbles are reported to increase the cleaning power of the washer in several ways: 1) by inducing a high-frequency pressure fluctuation near the clothes, 2) by increasing the dissolution of detergent, 3) by increasing the amount of dissolved oxygen which increases the activity of the detergent, and 4) by lowering the viscosity of the wash water [35][36].

The Sharp Corporation also makes a bubble washer in which the bubble-generating device uses neuro-fuzzy logic controls. From a nozzle located at the bottom of the washer, air bubbles are generated by a computer-controlled pulsator and circulated upward in vertical and horizontal swirling motions. The controls adjust the amount of water use by using a single-tub design that washes the same amount of laundry as a typical dual-tub (inner and outer) configuration. Water and detergent use are only $70 \%$ of that used in conventional dual-tub designs. Although sold in Japan, this machine is not yet marketed in the United States [37]. Standardized and independent tests have yet to be conducted on the performance of the bubble- 
action system, therefore the energy saving potential and performance of a bubble action design option is unknown.

This design option was proposed because of reports that such a machine was being manufactured in Korea and Japan. However, since there do not appear to be any energy savings studies from this design option, this design option is eliminated from further analysis.

\section{Ozonated laundering}

Currently, three manufacturers make ozonated laundering systems for commercial/institutional washers. The ozone, manufactured from ambient air, is injected into the water. There is some debate as to how the process of the ozonated cleaning exactly works. Some claim the ozone reacts with soluble soils, making them insoluble, after which the mechanical action of the washing separates the soils from the fabric. One manufacturer proposed that the energy inherent in ozone reduces water tension, making the water a better solvent. Energy is saved with this system because the water is not heated for light to moderately soiled laundry; in fact colder water retains a higher concentration of ozone for a longer time. For heavily soiled laundry, temperatures of $100-110^{\circ} \mathrm{F}$ are used. Also, since less chemicals are used, the rinse time is minimized thereby reducing the total wash time. Economical ozone production is critical to the potential energy savings. One manufacturer estimates savings of $25 \%$ on "utility expenses" with installation of its system. The expected cost and energy consumption for a residential ozonated wash system are unknown [38].

There does not appear to be any commercially available or working prototype residential clothes washer using this design option. Therefore, this design option is eliminated from further analysis.

\section{CONCLUSIONS}

For previously stated reasons, the design options in Table 4 were eliminated from further consideration. 


\title{
Table 4. Design Options Eliminated from Further Analysis
}

\author{
Improved Water Extraction for RMC's of 35\% \& 30\% \\ Suds Saving \\ Reduced Thermal Mass \\ Electric Disassociation of Water \\ Ultrasonic Washing \\ Bubble Action \\ Ozonated Laundering
}

Table 5 shows the design options remaining for further analysis.

\section{Table 5. Remaining Design Options}

\author{
Improved Fill Control \\ Tighter tub tolerance \\ Thermostatically controlled mixing valves (TCMV) \\ Improved Water Extraction for RMC's of 50\% \& $40 \%$ \\ Horizontal axis design \\ Horizontal axis design with recirculation \\ Automatic Fill Control \\ Increased Motor Efficiency \\ Direct Drive Motor \\ Advanced Controls / Sensors \\ Added Insulation
}




\section{REFERENCES}

1. U.S. Department of Energy (DOE). 1996a. Procedures, Interpretations and Policies for Consideration of New or Revised Energy Conservation Standards for Consumer Products; Final Rule. Federal Register Vol. 61 No. 136, Appendix A to Subpart C of Part 430 -July 15, 1996.

2. U.S. Department of Energy (DOE). 1994. Advance Notice of Proposed Rulemaking, Federal Register, Vol. 59, No. 218, 10 CFR Part 430, Docket No. EE-RM-94-403, November 14, 1994.

3. U.S. Department of Energy (DOE). 1991. Energy Conservation Program for Consumer Products: Final Rule Regarding Energy Conservation Standards for Three Types of Consumer Products. Code of Federal Regulations, Title 10 Part 430, Vol. 56, No. 93, May 14, 1991. Docket No. CE-RM-88-101.

4. Ibid.

5. U.S. DOE. 1994. Op cit.

6. U.S. DOE. 1996a. Op. cit.

7. U.S. DOE. 1996b. Energy Conservation Program for Consumer Products: Test Procedure for Clothes Washers and Reporting Requirement for Clothes Washers, Clothes Dryers, and Dishwasher. (61 Federal Register 17589, April 22, 1996.), 10CFR, Part 430, Docket No. EERM-94-230A.

8. Science Applications Inc., 1977. Energy Efficiency Program for Clothes Washers, Clothes Dryers and Dishwashers, SAI-77-839, La Jolla, CA. p.4-45.

9. Association of Home Appliance Manufacturers (AHAM). 1995. Comments on the Advance Notice of Proposed Rulemaking. DOE Docket No. EE RM-94-403, comment \#27, May 8, 1995.

10. U.S. DOE. 1996b. Op cit.

11. AHAM. 1996. Comments on the Supplemental Notice of Proposed Rulemaking, Energy Conservation Program for Consumer Products: Test Procedure for Clothes Washers Test Procedure, DOE Docket No. EE-RM-94-230A, comment \#7, June 6, 1996.

12. Ibid.

13. Arthur D. Little, Inc. (ADL). 1995. Laboratory Testing of Clothes Washers, p.3-8, December, 1995, EPRI Report No. TR-105098. 
14. U.S. DOE. 1996b. Op. cit.

15. U.S. DOE. 1996c. Federal Register, April 24, 1996, Volume 61, Number 80, Office of Energy Efficiency and Renewable Energy [Case No. CW-004]. Energy Conservation Program for Consumer Products: Granting of the Application for Interim Waiver and Publishing of the Petition for Waiver of General Electric Appliances from the DOE Clothes Washer Test Procedure.

16. Consortium for Energy Efficiency (CEE). High Efficiency Clothes Washer Initiative, Qualifying Products as of 7/9/96.

17. ADL. 1995. Op. cit.

18. B. Lebot, I. Turiel, G. Rosenquist. 1990. "Horizontal Axis Domestic Clothes Washers: An Alternative Technology that Can Reduce Residential Energy and Water Use". Proceedings of the ACEEE 1990 Summer Study on Energy Efficiency in Buildings, Volume 1, Building Equipment and Appliances, p.1.147-1.156.

19. A. Cahn. 1994. The Laundering Process, handout presented at the Workshop on Home Laundry Energy Standards Regulatory Issues, Washington, D.C., November 11, 1994.

20. Procter \& Gamble, Comments on the Advance Notice of Proposed Rulemaking, DOE Docket No. EE RM-94-403, comment \#9, January 20, 1995.

21. AHAM. 1995. Op. cit.

22. Electrolux product literature. New for '93, Domotechnica.

23. U.S. DOE. 1996b. Op. cit.

24. Appliance Manufacturer, April 1995, p.27.

25. Appliance Manufacturer, February 1995, p.E-58

26. Appliance, "New Ways of Washing", September 1992, Vol. 49, No. 9, p.75.

27. Appliance, September 1995, p.51.

28. Maytag 1996. Comments on the Supplemental Notice of Proposed Rulemaking, Energy Conservation Program for Consumer Products: Test Procedure for Clothes Washers Test Procedure, DOE Docket No. EE-RM-94-230A, comment \#8, June 6, 1996.

29. Raytheon 1996. Comments on the Supplemental Notice of Proposed Rulemaking, Energy Conservation Program for Consumer Products: Test Procedure for Clothes Washers Test Procedure, DOE Docket No. EE-RM-94-230A, comment \#9, June 6, 1996. 
30. S. Kristic, J. Pardee, "Direct" Comparison Assessing the Energy Efficiency Impact of a Transmission-Less Motor-Drive System for Conventional Clothes Washers, Proceedings of the 44th Annual International Appliance Technical Conference, p.101, May 1993.

31. U.S. DOE. 1990. Technical Support Document: Energy Conservation Standards for Consumer Products: Dishwashers, Clothes Washers, and Clothes Dryers, p.3-14, DOE/CE0299P, December 1990.

32. Ibid. p.3-15.

33. Ibid. p.3-15.

34. Ibid. p.3-15.

35. Appliance Manufacturer, "Big Plans for Tiny Bubbles", p.32, December 1994.

36. Appliance, "Sorting Through Laundry", p.35, September 1994.

37. I. Turiel, et al., Evaluation of Advanced Technologies for Residential Appliances and Residential and Commercial Lighting, January 1995, Lawrence Berkeley National Laboratory, LBL-35982.

38. Electric Power Research Institute (EPRI). 1996. Ozone Laundering: A Better Wash Process for Commercial Laundries, Technical Brief RP2890, March 1996. 